\title{
Review
}

\section{The democratic theory of Hans-Georg Gadamer}

\author{
Darren Walhof \\ Palgrave Macmillan, Cham, Switzerland, 2017, xv+145 pp., \\ ISBN: 978-3-319-46863-1
}

Contemporary Political Theory (2018) 17, S131-S134. https://doi.org/10.1057/s41296017-0124-0; published online 27 June 2017

Darren Walhof's book is a lucid and timely addition to the literature, and will be of great interest to scholars and students of Gadamer and democratic theory. Indeed, some of his comments on American political discourse have an eerily prophetic quality: no doubt at the time of writing we lived in a world 'marked by the reproduction of falsehoods', (p. 11) stoking nationalist and isolationist sentiments (p. 128), but these asides are prescient following the tumult of Britain's vote to withdraw from the EU and the US election result. Although some of the arguments would have benefitted from further elaboration, the book clears up common misconceptions and contains many insights, which deserve to be extensively discussed.

The main thrust of Walhof's book is that there are elements of life which remain unrecognised by contemporary political philosophies. His intent is not to criticise these approaches but instead to bring them into dialogue with Gadamer's hermeneutic project. This presents a problem since Gadamer is not commonly thought of as a political philosopher, and this is where Chapter 1 begins. Walhof explains Gadamer's criticism of the modern theory - practice divide and his definition of practical philosophy with reference to Plato's allegory of the cave (pp. 2-9). Gadamer considered practical philosophy to be 'the practice of paying attention to the realities of social and political life' (p. 2) and so considered his own work as intrinsically political. Walhof engages the misconception that Gadamer advocated a kind of social conservatism early in the book by explaining that his theory rejects the romanticising of the past, while at the same time refusing to conceive of the past as 'merely conservative' (p. 10). This is explored in detail later (pp. 85-88). The chapter also outlines Walhof's main contribution: the marriage of hermeneutic and democratic theory (pp. 9-12). Modern theorists, he argues, must consider (1) the possibility of disclosure of truth through dialogue; (2) the possibility of achieving understanding through dialogue; (3) the force of tradition in society and politics; and (4) the reality of solidarity and the ways in which we are

(C) 2017 Macmillan Publishers Ltd. 1470-8914 Contemporary Political Theory Vol. 17, S3, S131-S134 
bound to one another as members of a community. Walhof takes these points as the topics of the subsequent chapters.

In Chapter 2 Walhof sets about exploring Gadamer's notion of truth as something disclosed in language, and chiefly through dialogue. He explains that Gadamer's main thesis in Truth and Method is that many aspects of life cannot be reduced to objects in the way that the methodical approaches employed in the sciences suggest. This is not to say that methodology is not important, but merely that 'there is truth beyond method' (p. 14). Simply put, truth is 'sedimented' in language and 'disclosed' through dialogue (pp. 18-36). According to Walhof, it is not the case that language is something separate from us, which we make use of to communicate our 'preexisting thoughts', but that language enables and constrains our knowledge and expression (p. 20). To learn a second language is not simply to find new ways to express what we already know, but to enter a new system that allows us to learn things we otherwise could not. This is how Walholf intuitively introduces Gadamer's concept of 'horizons': the key argument is simply that a proposition does not contain truth in and of itself, but that meaning is drawn from a particular context (pp. 26-27). While saying that a particular sound or gesture is meaningless without a context (i.e. the horizon of a language) might seem superficial, Walhof's insight is that it bears significant consequences for democratic processes.

Indeed, Walhof proposes that deliberative theories of democracy place excessive epistemological demands on citizens. For him, these burdens result from two key requirements: that citizens form a given view on a subject, and that they provide generally acceptable reasons for their views (p. 52). The problem is that this process preempts understanding and agreement. In this model, the other party exists only so that the citizen may prove themselves correct about something, or, in other cases, merely as a source of information (p. 39). Conversely, Gadamer's phenomenology of conversation suggests that, when entering a genuine dialogue with someone, we relinquish control of the conversation and, in a sense, drift in directions we did not expect. According to Walholf, the critical difference between these two approaches is that in the former case citizens merely 'talk past each other' (p. 42). Having reflected on a subject in solitude, they come to the discussion with preformed ideas that they assume to be correct. In the latter, the very act of entering the dialogue means that one's own prejudices risk being exposed (pp. 45-46). They are not 'set aside in advance but are instead brought into play' (p. 49). This also builds on Walholf's discussion of the GadamerHabermas debate in that it demonstrates how we are not simply 'imprisoned in history and language' (p. 24). Further, the author provides compelling evidence that face-to-face encounters such as citizen's juries often lead to the kind of 'prejudice risking dialogue' he advocates (p. 55).

But it is not enough to simply identify an alien horizon, as mere recognition often avoids understanding altogether. The process of dialogue is one where the 
horizons of the participants meet and create a common language, which is not a precondition but a product of understanding (pp. 41-43). Critically, the understanding he discusses does not necessarily result in agreement (p. 42), and it is not simply that 'more talking' will solve persistent political problems (p. 70). The recognition that agreement is conflictual is agonistic in nature, and is present throughout the book (see e.g. Gadamer's 'coherence of tradition' and 'disequilibrium' on p. 89). It could have been advantageous to devote some discussion specifically to this particular quality of the theory. This, however, is a missed opportunity rather than a flaw.

And yet to what extent are we obligated to risk our prejudices? For example, a fundamental belief in the equality of persons may be an integral part of a citizen's horizon, a prejudice in the Gadamerian sense (i.e. a pre-judgement considered as a necessary condition for understanding, not a form of bias or bigotry). Would such a citizen be obligated to enter dialogue with, say, a white supremacist? The issue is not that a citizen might fear her egalitarianism would be 'disproven' in the course of debate, but rather, how can we ethically reflect on a citizen being asked to risk such a prejudice in the first place. Walhof clearly intends to promote dialogue in a system of 'pervasive partisanship' (p. 69), but he doesn't explore whether we might justifiably reject dialogue, for example, with chauvinists or fascists.

Chapter 3 lays out the deliberative model of view formation and reason-giving, while Chapter 4 explores how views are formed and what constitutes generally acceptable reasons. Walholf investigates the conflict between secular and religious reasons, including an alternative model of authoritarian and non-authoritarian reasons. (pp. 72-82). These dichotomies are wanting, however: we do not begin with 'with abstract consciousness or pure reason' but in medias res (p. 83). Walholf makes use of Heidegger's vernacular when he explains that we are 'thrown into a world from which we cannot extricate ourselves to gain an objective view' (p. 85). Therefore, religious beliefs are not simply a 'set of beliefs' so much as they are 'shaping habits'. Building on Gadamer's rehabilitation of the authority of tradition, Walholf argues that believers cannot have an objective consciousness of their attitudes, that they do not necessarily have 'reflective access' to these 'anticipatory commitments' (pp. 90-92). On this account, the deliberative approach essentially asks the impossible: for citizens to stand outside of themselves and offer 'acceptable reasons' that they may not believe in. While the author recognises this dilemma, he does not offer a solution.

Chapter 5 offers a novel examination of the purpose of the Occupy Wall Street movement, though it might seem belated six years after the fact. However, the application of Gadamerian solidarity to Occupy Wall Street as a kind of 'solidarity disclosing civic action' is intriguing (p. 100). Especially interesting is the discussion of solidarity and community. Walholf suggests that similarities between groups 'smaller and more local than the human race' are compelling precisely

(C) 2017 Macmillan Publishers Ltd. 1470-8914 Contemporary Political Theory Vol. 17, S3, S131-S134 S133 
because of the limits on our individual and collective experience (p. 112). Although the arguments contained in the chapter feel less forceful than those in the previous two, it remains a persuasive call for democratic revival through 'reciprocal coperception' (p. 114), through cooperation and dialogue.

I can recommend this book to both scholars interested in Gadamerian hermeneutics and modern democratic theory. Walhof's central argument that contemporary political philosophies ignore social and political realities is persuasive and more pressing than ever. Bringing Gadamerian concepts into dialogue with democratic theories calls attention to the weaknesses of a classically deliberative approach while highlighting the utility of genuine dialogue. Moreover, the exploration of the force of tradition is particularly original and will no doubt stimulate further discussion. On the whole, Walholf's book clears up common misapprehensions about Gadamer's work while contributing significantly to the literature.

Joshua Badge

Deakin University, Burwood, VIC 3125, Australia j.badge@deakin.edu.au 